\title{
From Scorching Desert to Tropical Paradise: New Form of Video Game Orientalism in Far Cry 3
}

\author{
Angga Prawadika Aji \\ | Communication Department, Faculty of Political and Social Sciences, Airlangga \\ University, Kampus B Dharmawangsa Dalam, Airlangga, Kec. Gubeng, Kota SBY, \\ Jawa Timur. Bisa dihubungi melalui email: angga.prawadika@fisip.unair.ac.id
}

\section{ABSTRAK}

This paper provides an analysis of different form of orientalism found in the third title of the popular Far Cry game series. The open world system offered by Far Cry 3 brings a new nuance in the discourse of orientalism in video games, especially within the context of military shooter game. It provides both opportunities and challenges for developers to build 'world' as real as possible for players to explore. This construction process often reflects the orientalism practices shown by game developers in describing Eastern society and culture. Through a variety of activities such as hunting, exploring, sailing, and killing enemy forces, the player acts as a 'western mediator' who intepret the simulated Eastern world as a strange and mysterious territory.

Keywords: video games, shooter game, orientalism, open world games, game studies

\section{Introduction}

The issue of orientalism within game studies still being a marginal issue that has not been much discussed. Cultural imperialism and ideological discourse in video games is still rarely discussed compared to other power inequality issues, such as gender and race. However, major shifts in the video game industry, both in terms of technological and narrative developments have encouraged new game variations that present new problems from the perspective of Orientalism west-east relations. Video game consumers continually demand original and different gaming experiences, which in turn game developers exploit various other socio-cultural elements to present exotic and exploratory experiences. This research seeks to see the new exploitation process carried out by the video game industry towards eastern cultural images through the eyes of Edward Said's Orientalism in the case of Far Cry 3.

Some studies have begun to explore the themes of orientalism and postcolonialism in video games although still few in number. Previous researchs such as the work of Christoper Douglas focused on the issue of domination and ideological struggle in the Civilization III strategy game, where the principles of colonialism and western world domination were also finally 'forced' on oriental countries with colonial history (Douglas 2002; Galloway 2004). In another study, 
Mirt Komel discusses how orientalism perceptions of the historical figure of Assassin as a proto terrorist were later transformed into generic western hero characters in the game Assassin Creed "-'(Komel 2014). Another study prefers focusing on how game developers rely on the principle of letting foreign cultures create elements of conflict (Schwartz 2006). An interesting research was conducted by Johan Hoglund on the issue of new American neoorientalism in a military shooter game (Hoglund 2008). Hoglund states that the game with the military shooter genre consistently presents the Middle East as a location for showdown and eternal conflict. Players always appear as stereotypycal American soldiers who have a duty to make this arid region filled with fanatic and barbarian figures become more 'civilized' by adopting a system of liberal democracy as in United States(Hoglund 2008).

Since Edward Said released his work Orientalism in 1978, the idea that Western civilization had described Eastern civilization objectively and neutrally started to be challenged. Orientalism implies an asymmetrical perception between the West and Orient, where Orient is described as a region with irrational, feminine, and psychologically weak character throughout the history of Western culture (Said 1978). Said defines "East" as a people who live in various regions of Asia, North Africa and the Middle East. Said adds that the relationship between "West" and "East" is in a constellation based on a specific configuration of power, influence, along with the assumption of domination (Said 1978) that ultimately combines imagination and desires of domination into a distinctive form of cultural imperialism. Therefore, Orientalism has become the main source of inaccurate cultural representation made by the Western World in the Orient regions, especially the Middle East region.

Just like other media, such as films and literary works, videogames cannot be excluded from the framework of orientalism. One of the most easily identified orientalist form in video games is the process of Eastern exoticization by the West "(Tucker 2008). Eastern civilization is constructed as an amazing and mysterious foreign entity through the lens of Western cultural imperialism. This process is facilitated by the presence of a central protagonist who originates, or at least has the characteristics and outlook, of Western civilization. This figure will then perform the task as a translator as well as a mediator to interpret Eastern civilization. A bridge that observer will use to make sense of the differences between the two cultures. The clearest illustration to explain this idea is the presence of the central figure, Nathan Algreen, played by Tom Cruise in the film Last Samurai. From the point of view of this Western mediator, the 'strange and miraculous' construction of the East makes sense, and in the end reflects the idea of orientalism as a whole "(Tucker 2008).

The geopolitical shift in global relations in the mid-20th century started an emerging interest in the idea of Orientalism. The political and cultural change of American society has also marked the process of inheriting the traditions of orientalism previously held by Europe. This new form of Orientalism is known as Neo-Orientalism 
(Hoglund 2008). This exact definition and scope of this term is still debated, but there are two characters that mark the emergence of neoorientalism. The first is the emergence of a massive and close relationship between the ideas of orientalism and the entertainment business. The second is a shift in focus that specifically leads to the Arab-Muslim world, which is characterized, one of which, by the stereotyping process of Middle Eastern society into too simplified representation (Said 1998). Several studies have been carried out previously to confirm the forms of neo-orientalism in various media, one of which focuses on the military shooter video game genre '"'"' (Hoglund 2008; Sisler 2008; Zwieten 2011; Mantello 2013; Stahl 2006; Tucker 2008).

It is undeniable that the first-person shooter game genre has become one of the most popular genres in the video game industry. Since the success of Doom by id Software developer in 1993, this genre has grown so rapidly beyond other genres. First-person shooter genre is the most widely produced game genre after the action genre in 2016 (Gough 2016). The popularity of first-person shooter game is supported by the development of visual technology that allows for a more realistic graphic and game mechanic. Technological developments also open up vast opportunities for game developers to present a more convincing process of diegesis. The ability for video game developers to create realistic modern warfare eventually opens up opportunities for a partnership between the video game industry and the government, especially the military. For nearly three decades, several games such as Full Spectrum Warrior (2002), Tom Clancy Rainbow
Six: Rogue Spear (2001), the popular series Call of Duty (2003-2019) and Battlefield (2002-2018) have long been used as recruitment and training instrument for United States Army '"'!'"'(Mantello 2013; Power 2007; Stahl 2006). Video games are considered capable of providing simulation to soldiers about what it feels like to be involved in modern combat. Endless pressure from consumers also forces game designers to create more realistic game mechanics and narratives. As a result, game designers began to rely on actual military conflicts, realistic adaptations of military strategies and equipment, and supporting elements such as factual reports of soldiers and veterans who are presented to support the realism of the game "''(Power 2007). Although game developers always offers new variations both in combat mechanic or narratives, the majority of military shooter games try to use contemporary armed conflicts as their backgrounds, such as Afghanistan, Iran, Pakistan, and Yemen '-'(Zwieten 2011; Riegler 2010). This exploitation process of the conflict ultimately presents a discursive American neo-orientalism where military-themed electronic entertainment is often characterized by the depiction of the Middle East as a frontier zone where a continuous war erupts between the United States and fanatical Muslim terrorist groups (Hoglund 2008; Sisler 2008).

Military shooter-themed video games consistently feature Middle Eastern people in two simple images, between corrupt and greedy oil entrepreneurs or radical terrorist groups (Said 1998) Middle Eastern cities that set the environment in video games are almost certainly 
shown as an endless labyrinth where terrorist members armed with old AK-47 weapons ready to attack behind every turn. According to Thomas Riegler, military shooter-themed games in the last two decades have at least a few key narratives that are closely related to the issue of terrorism; the elements that are directly related to the discourse of American neo-orientalism -'(Riegler 2010). First, it is an attempt to dramatize and glorify the the War on Terror launched by President Bush after 9/11. Second, military shooter game supports the use of forbidden covert operations against terrorism, such as carrying out torture and assassination and actively setting aside more peaceful options, such as negotiations or diplomatic efforts "'"(Power 2007). Third, military shooter game relies on elements of using secret special forces that have access to high-level technology to destroy the enemy. The enemy is displayed inferiorly, both in terms of experience and equipment. Lastly, military shooter games always support the idea that stability, prosperity and global security depend on the efforts of the Super Power state to destroy the forces of 'evil' in pockets of chaos, such as failed and chaotic states in the Middle East or dangerous forest criminal dens in South America and East Asia -'(Riegler 2010). These four elements directly strengthen the neo-orientalism discourse within military shooter games. The Middle East is described as a 'fantastic' area filled only with terrorists who want nothing but the destruction of the United States.

Hoglund's ideas about the issue of orientalism in a shooter game are interesting to be used in an analysis of Ubisoft's Far Cry 3. At a glance, Ubisoft's Far Cry 3 (2012) looks like a common first-person shooter genre video game. Nevertheless, Far Cry 3 shows a different view of orientalism because it displays an open world system where players are free to explore the virtual landscape modelled after Pacific islands. Far Cry 3 offers a new form of orientalism in the military shooter genre, shifting from the exploitation of the Middle East region accompanied by narratives of geopolitical conflict of fanatical Muslim Arab to the exploration of the exotic, primitive, sacred, and naive Pacific islands. The open world system and the unique narrative offered by Far Cry 3 also provide new opportunities to explore how game developers apply the idea of orientalism as a "subtle but persistent Eurocentric prejudice" (Marandi 2009) in portraying political and socio-cultural conditions of the Pacific Island community as a setting of armed conflict.

The popularity of the Far Cry game series itself is reflected in the continuity of this series since it was first released in 2004. Ubisoft has released 13 titles under the banner of the Far Cry series, with the latest one entitled Far Cry: New Dawn which was released in February 2019. Far Cry game series does not have a uniform and integrated narrative element among the 13 titles released; however, all of them have at least two significant characters which later became the hallmark of this series. First, this game always puts the players in a wild environment where they must survive against various natural elements, such as wild animals and weather changes. Second, the narrative of the game focuses on efforts to bring down one or more despotic antagonist characters in a particular area through various acts of armed 
violence. The popularity of this villain's characters has also been a major element driving the popularity of the Far Cry series, such as the pirate leader Vaas Montenegro (Far Cry 3), tyrant king Pagan Min (Far Cry 4), and cult leader Joseph Seed (Far Cry 5)

The author focuses on the third game of Far Cry 3 series for several reasons. First, Far Cry 3 marked a significant change which then defined the character of the Far Cry series. Far Cry 3 was the first Far Cry game series to capitalize the potential of the open world system to deliver a believable, alive, and breathing world in shooter game. According to the developer of the Far Cry series Dan Hay, the world of Far Cry 2 was indeed wide and open to be explored, but it still seemed 'bland' and lacked reaction to the players' actions. Far Cry 3 sought to learn from these shortcomings by presenting an 'actual civilization' where the player can feel the reality of the conflict and all the consequences it brings with it(Dyer 2013). In other words, the developer of Far Cry 3 tried to construct an image of the civilization of Pacific orient island society through a series of semiotic elements that can be analyzed throughout the game. Second, it is about the narrative presented within game itself. The narrative setting of Far Cry 3 is located in fictitious tropical island, called Rooks Island. The central main narrative of Far Cry 3 is the struggle of a young American named Jason Brody who seeks to save his friends from the hands of pirates and drug cartels who also oppress the Rooks Islands people. This narrative presents the player in the perspective of a typical western hero in exploring a tropical cultural region which is 'foreign, dangerous, superstitious, but also extremely tempting and seductive'. These two reasons clearly represent the continuation of orientalist discourse in first person shooter games like Far Cry 3.

The first part of this paper presents an introduction to the discourse of orientalism within video games studies. The idea of cultural imperialism over oriental territories is embedded in a game narrative that tends to support patronization and perpetuate Western supremacy. Video games have grown into a mainstream media which steadily growing more powerful and influential in spreading the complexity of discourse and ideology of hegemony -'(Leonard 2015). The second part goes to the development of shooter game genre and the popularity of the idea of neo-orientalism which emerges through the depiction of the Middle East region as an area of eternal conflict. In the last part, the author will discuss how Far Cry 3 offers a new form of orientalism through the portrayal of Pacific islander culture as an area of uncivilized and primitive society. Therefore, it must be organized and homogenized into a single unit -'(Riegler 2010) with the help of player as Western agent.

\section{Methodology}

This research uses the CDA (Critical Discourse Analysis) method from Norman Fairclough. This method was chosen because it is considered to be able to explore the discourse of power imbalance in the game's narrative text through an analysis that involves both the elements in the text itself and the various contexts 
that influence it. In accordance with the method offered by Fairclough, video game as a can be peeled through three conceptual layers. The first layer (micro layer) is the game text itself which serves as a description of textual analysis. The second layer or meso layer is the process of production and consumption of text, it can be said as an aspect of social agency in the production and consumption of texts. This is an analysis of the production process that is related to the values held by game developers in the game development process and how the game consumed by players and influences the reading of the text. This second layer serves as an interpretive tool to identify social agents, namely game developers and game players in reading alternative discourse in the game through the background of individual personal and social contexts. The third layer or macro layer is the socio-cultural context that surrounds the text, functions as an explanation or explanation of the semiosis and social practices that influence the production of the text.

In CDA, both social structure and social events are considered as an integral part of social reality. Social practices are a more stable and sustainable form of social activity, articulated together to constitute the social environment, institutions and organizations (Fairclough 2003). There is a semiotic dimension at each level of social practice. Language, and other semiotic systems such as visual semiotics and body language, are a certain type of social structure. Video game is one of the semiotic visual texts that can be analyzed to see ideological discourse playing within.

\section{Results and Discussion}

There are two things that need to be underlined before we jump to the discussion. First, Far Cry 3 is not a military shooter game per se. However, in terms of mechanics, aesthetics, and narrative, Far Cry is very close to the military shooter genre. This means that vis-a-vis comparison with military shooter-themed games is reasonable. Far Cry 3 players use a variety of weapons, both firearms and melee weapons, which are factual and displayed in as much detail as possible. The second socio-political theme presented in the game narrative indeed reflects contemporary conflicts that occur in real terms, e.g. the involvement of $\mathrm{CIA}$ agents in the struggle for political influence in conflict areas and the use of mercenaries as security services.

The second issue is related to the setting of Far Cry 3 which takes inspiration from the Pacific Islands. This reasoning does not necessarily explain a 'new orientalism' which is different from American neo-orientalism which emphasizes the portrayal of the Middle East region. The setting of remote tropical islands has actually been used several times in various titles of shooter video game genre, including Contra (1987), Crysis (2007), various titles from the Tomb Raider series (1996-2018), Call of Duty: World at War (2008), and even the first title of the Far Cry series itself (2004). The reason that makes Far Cry 3 interesting to discuss is the presence of 'simulated culture' of Pacific island societies that can be analyzed with Orientalism point of view. The Pacific island community, which is the setting of Far Cry 3, is described as being naive, primitive, violent, 
despotic, superstitious, and powerless compared to both the protagonist and antagonist figures who represent Western contemporary and progressive ideas. This depiction goes hand in hand with the process of interaction and exploration of players over the virtual world offered in the game. The new form of orientalism shown in Far Cry 3 can be deduced from the analysis of various aesthetic and narrative elements during the game process.

\section{New Form of Orientalism in Open World Game}

Far Cry 3 has a fictional tropical island set in the middle of the Pacific Ocean named Rooks Island. The background of the armed conflict that becomes the focus of the narrative game is on the dispute between the pirate forces and the drug cartel led by two main antagonists, Vaas Montenegro and Hoyt Volker against the local freedom fighter named Rakyat led by Citra Talugmai. The main protagonist in Far Cry 3 is Jason Brody, an American teenager trapped in conflict because he had to save his friends who were kidnapped by Vaas and Hoyt's troops. Far Cry 3 offers a non-linear narrative which involve multiple challenges, NPC characters, and factions that will determine the end of the game.

From the beginning, the Far Cry game series were built with the open world system, meaning that players can explore large areas freely, including determining when and how the objectives given in the game (Sefton 2008). Openworld games, or commonly confused with sandbox games, emphasize the elements of freedom and non-linear gameplay. The players will determine the flow and rhythm of their game according to their wishes. This freedom arises for example in the choice of how a particular mission is carried out, according to the style of play desired and the resources the player has. To support this type of game system, game developers strive to create a convincing 'world' as game main setting. A real-world simulation is made as closely as possible. The primary attraction open world game system is the presence of simulated reality where players can develop their characters and skills. Basically, every game with an open world system seeks to be able to create a world simulation where players can experience as serious an adventure as possible, complete with various details that support game experiences such as ecosystems, weather changes, infrastructure, to the cultural practices of people who run everyday life.

The leap of game technology that is now able to produce massive, engaging open world systems has actually provided a new space for the influence of orientalism. There are at least two main factors that support this statement. First, open world game provides an opportunity as well as a challenge for developers to produce a full world simulation, including various political, economic, and socio-cultural elements that support the narrative of the game. This process involves the process of interpreting, imagining, and representing by the game developer to a particular community culture that is intended to be portrayed. The depiction of the game's sociocultural background that focuses on Eastern societies then becomes interesting to be discussed. What is done by game developers is 
essentially equivalent to the efforts of European artists in the $18^{\text {th }}$ and $19^{\text {th }}$ centuries to record and interpret Orient culture on their journey (Said 1978). As explained earlier, Far Cry 3 was developed with efforts to create an 'actual civilization', in contrast to its predecessor, which was only able to present an bland world that lacked context and interaction.

The portrayal of Western superiority over the East is evident in how the Rooks Islands are displayed in Far Cry 3. The Rooks island community is a stereotypical picture of the peace-loving, naive, sensual, superstitious Oceanian society, but at the same time also savage and primitive. Pacific Islander races have long been the object of stereotypes in video games, where they are often shown as wrestlers and fighters - '(Leonard 2015). The interaction of protagonist Jason Brody has with local residents of Rooks reflects the meeting of European explorers in the $18^{\text {th }}$ and $19^{\text {th }}$ centuries with local tribes in the Oceanian islands. The exotic and seductive tropical island world of the Pacific is interpreted through the eyes of Jason Brody as a Western mediator.

An analysis of the framework of orientalism in term of the open world Far Cry 3 can be done by dividing the socio-cultural structure displayed in the game. There are three categories of community groups that are described as interrelated in the world of Far Cry 3. The first is the local population of Rooks Island. They are generally described as villagers working on daily activities such as farming, fishing, drinking, dancing, and listening to the radio. Innocent people are always described living in unarmed conditions, very poor, and appear to be uneducated. The main settlements of residents such as Amanaki and Badtown are almost entirely described as slums with houses made of old wooden boards and zinc sheets. This description is completely different from Thurston Town. It is the only settlement in the territory of enemy troops. The city is described as appearing to be richer, professional and modern and supported by highquality security technology. This description seems to support the idea that the path of modernization and technological development brought into the Rooks Islands depending on exploitative western armed forces. The naive and weak local people of Rooks Island are depicted to be unable to make any changes, even giving up and preferring to wait for intervention by the protagonists which incidentally originated from Western civilization.

The second group is freedom fighter, The Rakyat. Rakyat can be simply described as a military-religious fraternity group that acts as a resistance force of the indigenous people of Rooks Island. One significant marker between ordinary locals and Rakyat is the use of tattoos on the face. These ritualistic tattoos confirm that the inspiration of the people is taken from a combination of wild, primitive, and savage New Zealand Maori and Dayak Borneo warriors. The main character shown by Rakyat is absolute obedience to the charismatic figure of Citra Talugmai, the leader of the resistance who also acts as the religious leader of the indigenous people of Rooks Island. In general, Rakyat can be interpreted as the 'dark side' of the overall view of Pacific Rooks Island culture. Rakyat warriors always use weapons, violence, supernatural 
experiences, hidden rituals, and illegal drugs. Rakyat warrior is described as a 'noble savage' who is actually incompetent in taking the fight and defending themselves; thus, they must rely on a variety of 'heroic' actions of European protagonist. The relationship between Jason and residents of Rooks Island and Rakyat presents a duality of perception of the cultural conditions of Rooks Island. It is a beautiful, erotic, friendly and innocent island but also untouched territory that offers danger and death. It is in accordance with Driver and Martins' statements about the positive representation of tropical landscapes (extraordinary natural beauty) as well as the negative portrayal of tropical landscape as a pathological space of degeneration (Driver and Luciana 2005).

The third group is the antagonist faction which is the main source of conflict and the central narrative of the game. These antagonist troops initially controlled the entire Rooks Island archipelago. Their power and influence diminished gradually as the game progressed. There are two antagonist groups that are in the umbrella group of the Far Cry 3. The first is the pirate group led by Vaas Montenegro and the second is a professional mercenary group led by drug lord Hoyt Volker. It is interesting to discuss the asymmetrical perceptions that arise between these two antagonist groups. Vaas-led pirates are shown as a non-professional criminal group with low quality equipments and abilities. From the appearance of skin color, there is a strong assumption that this pirate group is a native of Rooks Island itself. It is a faction that rejects Citra's leadership and chooses to join criminal organizations rather than having to live below the poverty line. This appearance is very different in the troops led by Hoyt Volker. Hoyt's antagonist army consists of a group of professional mercenaries who are all white. The formulation of the antagonist group in Far Cry 3 appears consistently to place the local orient antagonists as fanatical and inexperienced troops which are only used as tools by Caucasian antagonists who are described as more modern, experienced, and organized. This portrayal is relevant with the image of a new US military formation after the Cold War that emphasizes smart weapons and experienced special forces. The vision of Western military forces that is "light, mobile, and deadly" is always confronted with new threats after the Cold War such as terrorist networks, drug cartels, guerrilla troops, warlords, and pirates -'(Riegler 2010).

The second factor that supports the strengthening of new form of orientalism in the open world game system lies in the principle of freedom of exploration. The most basic game mechanic is to stimulate players to explore, change the game environment as desired, and engage in various activities to reach the farthest limit of the game (Sicart 2008). The open world game system can present these three elements through the power of non-linear narrative appeal and the freedom to complete the game's objectives as the player's wishes. Far Cry 3 encourages players to explore the Rooks Island region through a variety of activities. Through these various side objectives, the players then act as a conduit to interpret the 'otherness' of Rooks Island. Through the activities of walking, shooting, 
harvesting, building, stabbing, sailing, hunting, navigating, opening maps, and establishing relationships with NPCs in the game, players explore and re-establish historical relations between identity and space (Lammes 2010). In Far Cry 3, the protagonist, Jason Brody, acts as an interpreter, who tries to link the rationality and establishment of the West with wild law in remote islands in the Pacific.

\section{Constructing Orientalist Narrative}

In addition to analysis that focuses on the open world systems, orientalism elements of Far Cry 3 can be analyzed through the aesthetic and narrative offered. The author will focus on the involvement of female characters in Far Cry 3 narrative because it is interesting illustration of how shooter game developers are beginning to adjust the picture of American neo-orientalism to a new form.

The issue of gender and race in the previous popular culture products, especially films and video games has been quite widely discussed in various studies '"-'(Jansz and Martis 2007; Mukherjee 2016; Dietz 1998; Leonard 2015; Kurnia 2017; Girsang 2020). Overall, it can be concluded that video games are dominated by masculine themes, such as action, war, violence, competition, and sports where women's portion and role tend to be minimal (Dietz 1998). In the previous research on orientalism in shooter game genre, Eastern women were only described in two simple versions. The first is a weak figure who is unable to fight back and is shown limited to emphasize the heroic actions of the player
(Hoglund 2008). In the majority of military shooter games, such as Call of Duty, Arma, or Soldier of Fortune, the main narrative of the game is always the struggle to overthrow tyrannical power through clandestine military actions -'(Hoglund 2008; Riegler 2010; Breuer, Festl, and Quandt 2012). Eastern women, often in a Middle Eastern country in both real and fictional settings, are only shown in a minimal portion to build a background of the tyranny and crime of the rulers who are the main antagonists of the game. These portrayals commonly appear in the form of mothers and children who look confused and frightened amid the destruction of infrastructure due to conflict. This description is a cliché about 'innocent people', whose death is a major crime and must be avenged. In addition, Eastern women often appear within the boundaries of emotional short cutscenes (cinematic non-interactive scenes) to build the player's anger over the narrative of 'the power of tyranny that must be overthrown'. In the second form, Eastern women are shown in a more active position and hold a more vital position in the entire narrative but only in a supporting character. These female characters are often displayed in a highly sexually formalized form as an exotic femme fatale as a supporting character for the majority of white male protagonists "'(Jansz and Martis 2007).

Both depictions reappear in Far Cry 3, although in quite different forms. In Far Cry 3, female characters can be divided into two categories. The first is female characters who play a vital role in the course of the main narrative. There are only three characters in this category, namely Liza Snow (Jason Brody's girlfriend), Daisy 
Lee (Liza's best friend and Jason Brody's brother's girlfriend), and most importantly Citra Talugmai (charismatic leader of Rooks Island). The second is female characters who only become extras and do not have a crucial role within the main narrative of Far Cry 3. The female characters of the Rooks island inhabitants are included in this category.

At a glance, the portrayal of the Rooks island women still reveals an old formula shown in various military shooter games. The Rooks Islands woman is described as a weak and helpless figure. There is but a single female member within paramilitary force of The Rakyat. The original women from Rook Islands are always shown as innocent citizens who cannot really understand the context of the violence that occurs around them. They are always portrayed as ordinary citizens doing domestic activities such as farming, listening to the radio, or selling goods at shop. Rooks island women are also described as having no position in the higher socio-political structure. This situation seems very contradictory to the position of the de-facto leader of the Rooks Islands, the woman figure of Citra Talugmai. The most obvious form of orientalism is seen in several locations such as Amanaki and Badtown, where young female rooks are displayed in wearing revealing clothes. They are depicted as attractive, shy, innocent, and give the impression of being a sexually submissive woman. This depiction is consistent with World War era pop-art in portraying women from exotic and arousing tropical islands. US soldiers who had visited Hawaii and fought in the Pacific (including conflicts in Indonesia, the Philippines, and later Vietnam) began to introduce a simple picture of a simple, innocent, untouched eastern woman, but teased through various artistic illustrations during the war, such as pin-up posters, magazines, to movies. In general, the appearance of Rooks Island native women objectified as 'eye candy' '"-'(Jansz and Martis 2007; Leonard 2015) can be seen as an exploitative attempt on Western masculinity in the appearance of Eastern women.

The portrayal of passive and weak women in Rooks Island is contradictory to one of the main characters in Far Cry 3, Citra Talugmai. She is a deuteragonist in Far Cry 3 and acts as the leader of the Rooks Island people's resistance to the pirates led by two main antagonists, Vaas Montenegro and Hoyt Volker. Unlike all the female characters of the Rooks islands who are passive and weak, Citra is portrayed as a strong, competent, and even dominant figure. She is depicted as a wild and primitive tribal chief, but at the same time, extraordinarily beautiful and charismatic. At a glance, the presence of Citra is a challenge to the narrative shooter game as a male world dominated by military masculinity, competition, and values of courage, discipline, and mental strength-'(Riegler 2010).

Citra is the strongest evidence of orientalism that appears in Far Cry 3. Although the entire population of the Rooks Islands has white skin with Asian complexion, Citra appears with dark skin and blue eyes. She wears primitive, revealing clothing complete with Rastafarian dreadlock haircuts. This character seems to have been formed with the aim of displaying 'oriental other', a figure easily identified by white protagonist as a symbol of a different Eastern world. An effort that reminds us of various classic 
Orientalist paintings that show the sensuality and mystery of Eastern women, such as The Snake Charmer (1880) and The Slave Market (1886) by Jean-LēonGērome. The presence of Citra as a primitive tribal chief who is seductive and defiant is the feminization of native Pacific women as a subordinate of white protagonists who are present as European explorers who represent civilized and rational life.

It is also important to see the comparison of narratives between Citra and two other main female characters in Far Cry 3, Liza Snow and Daisy Lee. Both Liza Snow and Daisy Lee are depicted in the stereotype of high-class white women who are educated and wealthy. One of the main conflicts that attempts to appear in Far Cry 3 is how ordinary people are trapped in violent armed conflict. This situation is displayed throughout the game from the interaction between the players who control Jason Brody and Liza Snow. Liza is shown as the voice of reason for the main protagonist. Although Liza does not have the ability to fight, she keeps trying to remind Jason to not fall into the brink of brutal violence and murder. Liza and Daisy are depicted as civilized occident women who represent the western position about logical arguments and clear minds (Said 1978, 1998). Both are anathema from the oriental figure of Citra, who is described as primitive and manipulative character and keep trying to control the main character by promise of power and sexual relationship.

Orientalism narratives in Far Cry 3 increasingly appear at the end of the game. The non-linear game system offered by Far Cry 3 ultimately forces players to choose between Liza or Citra. If the player chooses to defend Citra, Citra will manipulate the protagonist to kill Liza and all her friends. This version of the scenario ends with Citra having sex with Jason before killing him cruelly. Meanwhile, if the player chooses to save Liza and Daisy, Jason will ultimately leave Rooks Island with regret for all the violence he has committed during the game. The branching of choices and consequences of this narrative is an affirmation of the depiction of the image as a symbol of the brutal, unreliable, and betrayal oriental culture of the Pacific islands.

The orientalistic world and character construction are repeated by Ubisoft in the continued title of the Far Cry series, Far Cry 4 (2014). The game narratives shift from the Pacific islands to a fictional country in the Himalayas called Kyrat, which is culturally depicted very similar to Nepal or Bhutan. The main protagonist in Far Cry 4 is Ajay Ghale, a man of Kyrat descent who has lived all his life in America. The central of the story focuses on Ajay's involvement in the armed political upheaval between the Golden Path rebels who were once led by Ajay's father, and the government army led by the Pagan tyrant Min. This narrative formula is structurally very similar to the Far Cry 2 and Far Cry 3 series, which means that the orientalism elements that appear in Far Cry 3 can also be found in Far Cry 4. For example, the open world of Far Cry 4 also reconstructs Kyrat 'civilization', a backward Asian country that is a source of conflict and violence. As found in the Pacific Rooks Island culture in Far Cry 3, protagonist Ajay Ghale who was "born and raised in America" acts as a translator for players to interpret the extraneous and exotic Kyrat 
oriental culture. Therefore, it can be concluded that Far Cry 3 marks the beginning of a shift in a new form of orientalism that utilizes the ability of developers to create socio-cultural contexts in open world games.

\section{Conclusion}

Departing from the epistemological framework of Orientalism offered by Edward Said and then followed by a strong element of neoorientalism in various shooter videogame genre, we have seen how Far Cry 3 has an interesting position among similar genres: the open world system utilized in Far Cry 3 has offered players with complexity of narrative which gives a new nuance in the discourse of orientalism in the shooter video game genre. The findings from the analysis show that there is a shift in neo-orientalist exploitation in the open world first-person shooter game, where the construction of exotic, backward, and foreign eastern culture is developed in more depth through a variety of activities involving players and various narrative combinations. Open world systems provide both opportunities and challenges for developers to build 'world' as real as possible for players to explore. This construction process often shows the practice of orientalism by game developers in describing Eastern societies. Through the representation of game elements such as the environment and NPC (non-playable character), the developer of Far Cry 3 has presented the Pacific island culture as a naive, primitive, violent, despotic, superstitious, and helpless party. Oriental Pacific culture acts as a subordinate of the protagonists and antagonists who represent contemporary and progressive Western ideas. This depiction goes hand in hand with the process of interaction and exploration of players over the Oriental virtual world. Unlike the other shooter game titles, Far Cry 3 introduces a new mechanical system that invites players to interact with the wild Pacific islands. These activities, such as hunting, catching fish, gathering herbs, and solving puzzles guide players to perform exploratory simulations of the 'oriental alien world' which is trying to be built in Far Cry 3. These activities are extension of the process of interpretation and mediation of Western protagonist, Jason Brody, in interpreting the Pacific islands as a wild region primitive and dangerous. A conclusion is also confirmed from how the female character is displayed in Far Cry 3, where the portrayal of the femme fatale figure, Citra Talugmai, and the naive and seductive young woman Rooks Island shows that the elements of orientalism can be seen from the complexity of the narrative of the game.

\section{References}

Breuer, Johannes, Ruth Festl, and Thorsten Quandt. 2012. "Digital War: An Empirical Analysis of Narrative Elements in Military First-Person Shooters." Journal of Gaming \& Virtual Worlds 4 (3): 215-37. https://doi.org/10.1386/jgvw.4.3.21 5.

Dietz, Tracy. 1998. "An Examination of Violence and Gender Role Portrayals in Video Games: Implications for Gender Socialization and Aggressive Behavior." Sex Roles 38 (5-6): 425-42. https://doi.org/10.1023/A:10187099 05920. 
Douglas, Christopher. 2002. "'You Have Unleashed a Horde of Barbarians!': Fighting Indians, Playing Games, Forming Disciplines." Postmodern C u I t u re 13 (1). http://pmc.iath.virginia.edu/issue.90 2/13.1douglas.html.

Driver, Felix, and Martins Luciana. 2005. Tropical Visions in an Age of Empire. Chicago: The University of Chicago Press. https://doi.org/10.1111/j.14679493.2008.00331.x.

Dyer, Mitch. 2013. "The Development Secrets of Far Cry 3." Ign.Com. 2013. https://www.ign.com/articles/2013/ $01 / 30 /$ the-development-secrets-offar-cry-3.

Fairclough, Norman. 1995. Critical Discourse Analysis : The Critical Study of Language. New York: Longman Publishing.

- - . 2003. Analysing Discourse: Textual Analysing for Social Research. London: Routledge.

Galloway, Alexander R. 2004. "Social Realism in Gaming." Game Studies 4 (1). http://gamestudies.org/0401/gallow ay/.

Girsang, Lasmery R M. 2020. "Women as Opinion Leaders within Community : A Model of Feminism Perspective." Jurnal Aspikom 5 (1): 1-10. https://doi.org/http://dx.doi.org/10. 24329/aspikom.v5i1.546.

Gough, Christina. 2016. "Genre Breakdown of Video Game Sales in the United States in 2018." Statista.Com. 2016. https://www.statista.com/statistics/ 189592/breakdown-of-us-videogame-sales-2009-by-genre/.

Hoglund, Johan. 2008. "Electronic Empire: Orientalism Revisited in the Military Shooter." Game Studies 8 (1). http://gamestudies.org/0801/article s/hoeglund.

Jansz, Jeroen, and Raynel G Martis. 2007. "The Lara Phenomenon : Powerful Female
Characters in Video Games." Sex Roles $56(3-4)$ : 141-48. https://doi.org/10.1007/s11199006-9158-0.

Komel, Mirt. 2014. "Self-Orientalizing The Assassins from Forerunners of Modern Terroris m Into Occidentalized Heroes." Teorija in Praksa 51 (1): $72-90$. h tt $p: / / d k$. f d v. u n i lj.si/db/pdfs/TiP2014_1_Komel.pdf.

Kurnia, Novi. 2017. "CONSUMING GENDER AND DISABILITY." Jurnal Aspikom 3 (3): 570-87.

Lammes, Sybille. 2010. "Postcolonial Playgrounds : Games as Postcolonial Cultures." Eludamos Journal for Computer Game Culture 4 (1): 1-6. https://www.eludamos.org/index.ph p/eludamos/article/view/vol4no1$1 / 149$.

Leonard, David. 2015. "Not a Hater, Just Keepin ' It Real : The Importance of Race- and Gender-Based Game Studies." Games and Culture 1 (1): 83-88. https://doi.org/10.1177/155541200 5281910.

Mantello, Peter. 2013. "Legitimacy and the Virtual Battlefield: Putting the FirstPerson Shooter on the Witness Stand." Australian Journal of International Affair 67 (5): 37-41. https://doi.org/10.1080/10357718.2 013.817523.

Marandi, Seyed Mohammad. 2009. "Constructing an Axis of Evil : Iranian Memoirs in the ' Land of the Free.'" American Journal of Islamic Social Sciences 29 (2): 23-47. https://www.ajiss.org/index.php/ajis s/article/view/377.

Mukherjee, Souvik. 2016. "Playing Subaltern : Video Games and Postcolonialism." Games and Culture 13 (5): 1-17. https://doi.org/10.1177/155541201 5627258.

Power, Marcus. 2007. "Digitized Virtuosity: Video War Games and Post-9/11 
Cyber-Deterrence." Security Dialogue 38 (November 2004): 271-88. https://doi.org/10.1177/096701060 7078552.

Riegler, Thomas. 2010. "On the Virtual Frontlines : Video Games and the War on Terror." In Videogame Cultures and the Future of Interactive Entertainment, edited by Daniel Riha, 1st ed., 53-63. Oxford: InterDisciplinary Press.

Said, Edward. 1978. Orientalism. New York City: Pantheon Books.

---. 1998. "Islam Through Western Eyes." Th e $\mathrm{n}$ a tion. Com . 1998 . https://www.thenation.com/article/i slam-through-western-eyes/.

Schwartz, Leigh. 2006. "Fantasy, Realism, and the Other in Recent Video Games." Space and Culture 9 (3): 313-25. https://doi.org/10.1177/120633120 6289019.

Sefton, Jamie. 2008. "The Roots of Open World Game." Gamesradar.Com. 2008. https://www.gamesradar.com/theroots-of-open-world-games/.

Sicart, Miguel. 2008. "Defining Game Mechanics." Game Studies 8 (2). http://gamestudies.org/0802/article s/sicart.

Sisler, Vit. 2008. "Digital Arabs : Representation in Video Games." European Journal of Cultural Studies 11 (2): 203-19. https://doi.org/10.1177/136754940 7088333.

Stahl, Roger. 2006. "Critical Studies in Media Have You Played the War on Terror ?" Critical Studies in Media Communication 23 (2): 37-41. https://doi.org/10.1080/073931806 00714489.

Tucker, Elmer. 2008. "The Orientalist Perspective : Cultural Imperialism in G a m ing." Ga m e olog y. http://www.aughty.org/pdf/orientali st_perspective.pdf.

Zwieten, Martijn Van. 2011. "Danger Close : Contesting Ideologies and
Contemporary Military Conflict in First-Person Shooters." In Proceedings of DiGRA Conference: Think Design Play. Hilversum. 